Bu makaleye atıfta bulunmak için/To cite this article:

YIGĞITER, Ș. Y. SARI, S. S. BAȘAKIN, E. E. (2021). Türkiye'de İșlem Gören Firmaların Sukuk Verileri ile Karşılaştırmalı Zaman Serisi Analizi. Atatürk Üniversitesi Sosyal Bilimler Enstitüsü Dergisi, 25 (3),1232-1248.

\title{
Türkiye’de İşlem Gören Firmaların Sukuk Verileri ile Karşılaştırmalı Zaman Serisi Analizi
}

\author{
Şule Yüksel YİĞITER ${ }^{*}$ \\ Salim Sercan SARI ${ }^{* * *}$ \\ Eyyup Ensar BAŞAKIN ${ }^{(* * *)}$
}

Öz: Islami finans çerçevesinde sukuk son zamanlarda özellikle hızlı bir gelişme göstermektedir. Müslüman ülkelerde ortaya çıkan ve tüm dünyada giderek yaygınlaşan sukuk finans uzmanlarına birçok yeni çalışma alanı sunmaktadır. Genel olarak sukuk, İslamiyet'in ilk zamanlarında, ticari ilișkilerin düzenlenmesi adına bir takım alıșveriş usullerini kapsayan finansal bir kavram olarak ifade edilmektedir. Ülkemizde sukuk ihracı yapan işletmelerden 5 tanesi çalışmamızda ele alınmıştır. Çalışmada işlem gören bu şirketlerin fiyat verileri kullanılarak, gelecekte olması düşünülen fiyat değerleri tahmin edilmiştir. Bu tahmin kapsaminda şirketler arası korelasyonlardan yola çıkılarak en iyi ilişkiye sahip 3 şirket belirlenmiş, gelecekte olması muhtemel fiyat değerleri tahmin edilmiștir. Çalıșmada Bulanık Mantık yöntemi kullanılmıştır. Tahminler istatistiksel başarı kriterleri olan hata kareleri ortalaması (HKO) ve verimlilik katsayısı (VK) yardımıla test edilmiştir. Bulanık Mantık yöntemlerinin sukuk verilerinde kullanılması ile ilk olma özelliği taşıyan bu çalışmada, Bulanık Mantık yönteminin finans problemleri için uygunluğu bir kez daha kanıtlanmıştır.

Anahtar Kelimeler: Sukuk, tahmin, bulanık mantık.

\section{Comparative Time Series Analysis with Sukuk Data of Companies Traded in Turkey}

\begin{abstract}
In the Islamic finance framework, sukuk has emerged as a rapidly developing structure in recent times. Having emerged in Muslim countries and spreading all over the world, sukuk offers many new fields of study to financial experts who want to work in this area. In general, sukuk is expressed as a financial concept that covers a number of shopping procedures in order to regulate commercial relations in the early days of Islam. Five of the companies exporting sukuk in our country were dealt within our study. Using the price data of these companies, future prices were estimated. Within the scope of this estimation, out of the correlations between the companies, 3 companies with the best relations were determined and possible future price values were estimated. Fuzzy Logic method is used in the study. Estimates were tested with the help of statistical success criteria of error squares averages and efficiency
\end{abstract}

*) Doç. Dr., Erzincan Binali Yıldırım Üniversitesi İIBF İşletme Bölümü (e-posta: syigiter@erzincan.edu.tr) (DD ORCID ID. https://orcid.org/0000-0003-3230-5784

$\left.{ }^{* *}\right)$ Arş. Gör. Dr., Erzincan Binali Yıldırım Üniversitesi İİBF İşletme Bölümü (e-posta: salim.sari@erzincan.edu.tr) (D) ORCID ID. https://orcid.org/0000-0003-2607-5249

${ }^{* * *}$ Arş. Gör., İstanbul Teknik Üniversitesi İnşaat Mühendisliği (e-posta: basakin16@itu.edu.tr)

(D) ORCID ID. https://orcid.org/0000-0002-9045-5302

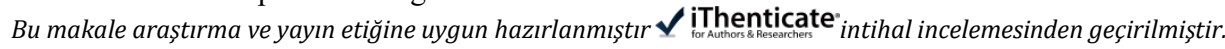


Şule Yüksel YíĞİTER

coefficients. In this study, which is the first to use Fuzzy Logic methods in sukuk data, the suitability of Fuzzy Logic method was proved once again for financial problems.

Keywords: Sukuk, Estimate, Fuzzy Logic.

Makale Geliş Tarihi: 08.11.2019

Makale Kabul Tarihi: 19.09.2021

DOI: 10.53487/ataunisosbil.644418

\section{Giriş}

Bilim ve teknolojideki ilerlemeyle birlikte hayatın her alanında büyük bir rekabet yaşanmaktadır. Sektör ayrımı olmaksızın, hemen hemen bütün işletmelerin rakiplerinin önüne geçebilmesi için kuvvetli bir finansal sisteme sahip olması gerekliliği daha iyi anlaşılmaktadır. Finansal yönden kuvvetli olan işletmelerin, karşı karşıya kalabileceği krizleri en az etkiyle atlatması söz konusu olacaktır. İşletmeler için finansman konusu göz ardı edilemeyecek kadar önemli bir konudur ve geleneksel finansman yöntemleri finansal problemlerin çözümü için tek başına yeterli olamamaktadır.

Gelişen teknolojinin finansal piyasaları da etkilemesi ile birlikte alternatif finansman yöntemleri etkin bir şekilde uygulanmakta ve aynı zamanda yeni finansman yöntemleri arayışı devam etmektedir. Ellerinde fon fazlası bulunan İslami düşüncedeki yatırımcılarda inançlarına uygun faizsiz finansman yöntemlerinden yararlanmaktadır. Bu finansman yöntemlerinden biri de "Sukuk"tur.

Son dönemlerde dünyada ve Türkiye' de sukuk enstrümanı yoğun talep görmektedir. Çalışmada, ülkemizde Sukuk ihracı gerçekleştiren firmalardan beş tanesinin verilerini baz alınarak, bulanık mantık yöntemiyle sukuk değerlerinin ileriye dönük tahmin edilmesi amaçlanmıştır.

İslami tahvil olarak adlandırılan sukuk, mevcut olan bir varlık veya varlık havuzu üzerinden sahiplik gereği gelir elde edilmesini sağlayan bir finansman aracıdır. Sukuk, gerçek bir varlığın sahipliğini veya fayda hakkını gösteren sertifika olarak ifade edilmektedir (IIFM, 2010: 3).

Körfez Ülkelerinin liderliğinde kurulmuş olan ve dünyada kabul gören İslami Finans Kurumları Muhasebe ve Denetim Organizasyonu (Accounting and Auditing Organization for Islamic Financial Institutions - AAOIFI) kuruluşuna göre ise sukuk; "mevcut varlıkların üzerindeki ortak pay ve hakların simgelendiği, herhangi bir yatırım faaliyetinde ortaklık hakkı veren, ulaşılacak tutarların daha evvel planlanmış biçime uygun olarak yatırım yapıldiğ ve hepsi eşit değerleri temsil eden sertifikalardır" (AAOIFI, 2010: 1).

Dünya'da sukuk ihracı ilk kez 1990 yılında Maleyza' da gerçekleşmiştir. İhraç edilen toplam sukuk miktarı 125 milyon Malezya Ringiti (30 milyon dolar) kadardır. Malezya' dan sonra birkaç girişim yaşanmasına rağmen 2000'li yıllarda yaşanan siyasi 
gelişmelere kadar sukuk ihracında bir durgunluk yaşanmıştır. 2000'lerde petrol satışından elde edilen gelirlerin finansal piyasalara yönlendirilmesini sağlamak amacıyla önemi tekrar ortaya çıkan sukuk, batıdaki finansal piyasa araçlarına alternatif olmuştur. Ortadoğu' da ilk kez 2001 yılında Bahreyn hükümeti 100 milyon dolar tutarında sukuk ihraç etmiştir (Shuaa Capital, 2007: 3).

Türkiye'de sukukla ilgili ilk yasal girişim 2010 yılında Sermaye Piyasası Kurulu tarafından gerçekleştirilmiştir. Sonraki dönemlerde kamu otoritesinin de desteğiyle sukuk ihraç rakamlarında dikkate değer bir artış yaşanmıştır. İlk sukuk ihracı Hazine tarafından 2012' de 1,5 milyar dolar olarak gerçekleştirilmiş, 2013 ve sonrasında da yurtiçi piyasalarda sistemli şekilde ihraç devam etmiştir (Hazine Müsteşarlığg).

\section{Literatür Özeti}

Sukuk gün geçtikçe finansal piyasalarda daha da dikkat çeken bir enstrüman haline gelmiştir. Sukuk ve çalışmada kullanılan yönteme ilişkin literatürde çok sayıda çalışmaya rastlanmaktadır. Ancak araştırmada kullanılan tahmin yönteminin sukuk ile ilgili bir çalışmada ilk defa kullanılması nedeniyle literatür için önemli olacağı düşünülmektedir.

Kimoto, Asakawa, Yoda, Takeoka (1990) çalışmalarında, Tokyo Menkul Kıymetler Borsası'nda hisse senetlerinin ne zaman alınıp satılacağı zamanlamasını yapan ve modüler sinir ağlarına dayanan bir tahmin sistemi ele almışlardır. Çalışma sonucunda tahmin sisteminin, olumlu sonuç verdiği ortaya çıkmıştır.

Kim, Han (2000) çalışmalarında hisse senedi fiyat endeksini öngörmek için özellik ayrıklığına genetik algoritmalar yaklaşımı ve yapay sinir ağları için bağlantı ağırlıklarının belirlenmesini önermişlerdir. Deneysel sonuçlar, özellik ayrıklaştırma modeline genetik algoritmalar yaklaşımının diğer modelden daha iyi performans gösterdiğini ortaya koymuştur.

Kim (2003) çalışmasında destek vektör makineleri metodunu hisse senedi fiyat endeksini tahmin etmek için uygulamıştır. Deneysel sonuçlar bu metodun borsa tahmini için umut verici bir alternatif sunduğunu göstermiştir.

Kim, Han, Lee (2004) yaptıkları çalışmalarında, makina bilgisi, uzman bilgisi ve kullanıcı bilgisi gibi çeşitli kaynaklardan bilginin optimize edilmiş entegrasyonu için bulanık genetik algoritmayı kullanan çalışmalarında, hibrid bilgi entegrasyon mekanizması önermişlerdir. Bu mekanizmayı, Kore hisse senedi fiyat endeksinin tahminine uygulamışlardır. Sonuçlar, hibrid mekanizmanın daha doğru ve daha az belirsiz sonuçlar sağlayabileceğini göstermektedir. Bu durum, mekanizmanın borsa gibi yapılandırılmamış bir ortam için birden fazla kaynaktan bilgi entegrasyonunda yararlı olduğu anlamına gelmektedir.

Huarng ve Yu (2005) çalışmalarında konvansiyonel bulanık zaman serisi modelleri yerine tahminlerde daha çok gözlemin kullanılabilmesini sağlayan bulanık zaman serileri modelinin kullanılmasını önermişlerdir. Sonuç olarak bu modelin daha iyi performans gösterdiğini göstermişlerdir. 


$1235 \begin{array}{lc}\text { Şule Yüksel YiĞ́̆ITER } & \text { A T A S O B E D } \\ \text { Eyyup Ensar BASSAKIN } & 2021 \text { 25(3): } 1232-1248\end{array}$

Cheng, Cheng ve Wang (2008) çalışmalarında, bulanık kümelemeye dayalı yeni birçoklu bulanık zaman serisi metodunu tanıtmışlardır. Sonuçlar, önerilen yöntemin yalnızca bir nitelikli değil aynı zamanda çoklu öznitelik verilerini de etkili bir şekilde tahmin edebildiğini ve listeleme yöntemlerinden daha iyi performans gösterebildiğini ortaya çıkarmıştır. Vadeli işlem tahminlerinin ampirik sonuçları önerilen yöntemin gerçek problemlerde etkin bir şekilde uygulanabileceğini göstermiş̧tir.

Chu, Chen, Cheng ve Huang (2009) çalışmalarında hisse senedi endeksini öngörmek için öngörme faktörleri olarak hisse senedi endeksini ve işlem hacmini alan çift faktörlü bulanık zaman serisi modelini önermiş̧lerdir. Sonuçlar, önerilen modelin hisse senedi endeksi öngörüsünde etkili olduğunu göstermiştir.

Liu ve Wei (2010) çalışmalarında mevsimlik zaman serilerini etkili bir şekilde ele alabilen gelişmiş bulanık zaman serileri tahmin yöntemi geliştirmeyi amaç edinmişlerdir. Önerilen yöntemi göstermek ve önerilen yöntem ile dört bulanık zaman serisi yöntemi arasındaki öngörü doğruluğunu karşılaştırmak için iki sayısal veri seti kullanmışlardır. Karșılaștırmanın sonuçları, önerilen yöntemin daha kesin tahmin sonuçları ürettiğini göstermiștir.

Wong, Tu ve Wang (2010) Tayvan ihracat probleminin tahmininde geleneksel zaman serisi metodu (ARIMA modeli ve ARMA modeli) ve bulanık zaman serileri metodu (İki faktörlü model, Sezgisel Model ve Markov modeli) önermişlerdir. Bulgularda, bulanık zaman serileri yönteminin, özellikle sezgisel model gibi kısa vadeli tahminlerde daha iyi tahmin yeteneği gösterdiği belirtilmiş̧tir.

Yu ve Huarng (2010) çalıșmalarında tahmin yapmayı iyileștirmek için yeni bir bulanık zaman serisi modelini uygulamayı amaçlamışlardır. Önceki çalışmalardan farklı olarak, bu çalışma, bulanık ilişkilerin kurulmasında ilişkilerin daha düzgün bir şekilde ele alınmasına yardımcı olan çeşitli derecelerde üyeliği kapsamıştır. Sonuç olarak bulanık zaman serileri modeli önerilmiştir.

Wang (2011) çalışmasında Tayvan ihracat değerlerini, ARIMA zaman serisi yöntemi ve bulanık zaman serisi yöntemi ile tahmin etmiştir. Sonuç olarak, yalnızca küçük bir veri seti ile örnekleme süresi kısaltıldığında, bulanık zaman serileri modellerinin, ihracat değerlerini ARIMA modelinden daha iyi tahmin ettiği görülmüştür.

Nan, Zhou, Kou ve Li (2012) çalışmada, bulanık kümelemeye dayalı çoklu bulanık zaman serileri için yeni bir sezgisel iki değişkenli tahmin modeli önermişlerdir. Alabama Üniversitesindeki kayıt, TAIEX gösterimi ve sensör veri seti üzerindeki deneysel sonuçlar, önerilen modelin çok serili harici serilerle etkili bir şekilde ilgilenebileceğini ve mevcut algoritmaların çoğundan daha iyi performans gösterdiğini ortaya koymuştur.

Zarandi, Hadavandi ve Turksen (2012) yaptıkları çalışmalarında gelecekteki günlerde hisse senedi fiyat tahmini için akıllı acentelerin koordinasyonuna dayanan 
hibrid yapay zeka modeli geliştirmeye yönelik dört katmanlı bulanık çok noktaya alıcı sistem (FMAS) mimarisi sunmuşlardır. Sonuçlar, FMAS'ın önceki yöntemlerin hepsinden daha iyi performans gösterdiğini ve dolayısıyla hisse senedi fiyat tahmini problemleri için uygun bir araç olarak görülebileceğini göstermiştir.

Hassan, Ramamohanarao, Kamruzzaman, Rahman ve Hossain (2013) çalı̧̧malarında doğrusal olmayan zaman serisi verilerini tahmin etmek için yeni bir tür uyarlanabilir bulanık çıkarım sistemi önermişlerdir. Önerilen yaklaşımın hisse senedi fiyat endekslerinin tahmininde etkili olduğu ortaya çıkmıştır.

Majhi ve Anish (2015) çalışmalarında aynı anda dört performans ölçütünü optimize eden uyarlanabilir borsa tahmini modellerini etkili bir şekilde eğitmek için çoklu nesnel parçacık sürüsü optimizasyonunu (MOPSO) ve tahsis edilmemiş sıralama genetik algoritma-II'yi (NSGA-II) tanıtmışlardır. Bu modellerden mümkün olan en iyi çözüme ulaşmak için, bulanık mantık temelli karar verme stratejisini önermişlerdir. Simülasyon sonuçları yakından incelendiğinde, MOPSO tabanlı modelin, NSGA-II modelinden üstün olduğu durumların daha fazla olduğu ortaya çıkmıştır.

Arundina, Omar ve Kartiwi (2015) çalışmalarında yatırımcıların, çeşitli derecelendirme kuruluşlarından yaklaşım ve tahvil derecelendirme konularında geçmiş araştırmalardan elde edilen dereceleri tahmin etmek için ampirik bir temel oluşturmuşlardır. Şirket mali oranlarından veya finansal özelliklerinden kaynaklanan çeşitli teorik değişkenlerden bir sukuk derecelendirme olasıllğı modelini oluşturmak için çoklu lojistik regresyon ve yapay sinir ağları (ANN) gibi istatistiksel ve yapay zeka yöntemlerini kullanmışlardır. Burada sukuk derecelendirme tahmini konusunda titiz sonuçların değerlendirilmesini amaçlamışlardır.

Sun, Guo, Karimi, Ge, Xiong (2015) çalışmalarında bulanık kümeler ve çok değişkenli bulanık zaman serileri metodunu kullanarak Çin hisse senedi endeksinin (CSI) gelecek fiyatlarını tahmin etmişlerdir. Sonuç olarak bir önceki güne iliş̧kin düşüşün ve spot hisse senedi fiyatlarının hisse senedi endeksi vadeli fiyatlarının düşmesi durumunda, ertesi gün borsa endeksi vadeli fiyatlarının arttığı, önceki günün borsa endeksi vadeli fiyatlarının yükselmesi ve spot fiyatların istikrarlı seyretmesi durumunda hisse senedi endeksi vadeli fiyatlarının ertesi güne kayma gösterdiği görülmüştür.

Wei (2016) çalışmasında zaman serisi tahmini, sistem modellemesi, hisse senedi endeksi tahmininde, ANFIS'in basitleştirilmesini amaçlayan modellemeyi geliştirmiş ve geleneksel zaman serileri modellerine kıyasla daha kesin tahmin sonuçları üretmiştir.

Nagano (2016) Malezya, Endonezya, Suudi Arabistan ve Birleşik Arap Emirlikleri'nden 2001-2013 döneminde temin edilen güvenlik ihraç verilerini kullanarak sukuk ihraççılarının konvansiyonel borç ve öz sermaye ihraççılarından ne kadar farklı olduklarını araştırmıştır. Sonuçta, gözlemlenen düşük finansal kısıtlamanın ve geçmiş değer öncesi hisse senedi fiyatlarının, ihraççının pazara erişilebilir olduğunu varsayarak sukuk ihraç etmeyi teşvik ettiğine kanıt bulunmuştur. 


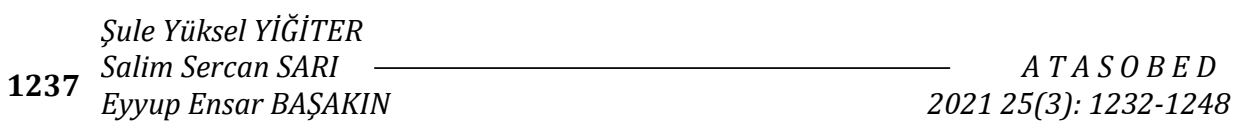

Smaouia ve Nechi (2017) 1995-2015 dönemini kapsayan tüm sukuk ihraç eden ülkelerden oluşan bir örnek kullanarak sukuk pazarının ekonomik büyüme üzerindeki etkisini araştırmışlardır. Sukuk pazarının, finansal piyasa gelişimi, kurumsal kalite ve ekonomik büyümenin klasik belirleyicilerinin çeşitli önlemlerini kontrol ettikten sonra bile, ekonomik büyümeye elverişli olduğunu gösteren güçlü ve sağlam kanttlara ve sukuk piyasalarının gelişmesinin, yatırım ve ekonomik büyümeyi tetikleyen dini kendi kendini dışlama olumsuz etkilerini ortadan kaldırarak finansal dahil olmasını sağladığı sonucuna ulaşıılmıştır.

Yiğiter, Sarı ve Başakın (2017) çalışmalarında BİST'de işlem görmekte olan hisse senetlerinin kapanış fiyatları zaman serileri aracılı̆̆ıyla bulanık mantık, yapay sinir ağları ve regresyon modelleriyle tahminini yapmışlardır. Yapılan analizlerle ANFIS modelinin diğerlerinden üstün olduğu tespit edilmiştir. Yapay sinir ağları ve bulanık mantık kullanılarak yapılan tahminlerin finansal olarak alınan kararlarda yatırımcıları bir adım ileriye taşıyacağı tespit edilmiştir.

\section{Materyal ve Metod}

\section{A. Bulanık Mantık}

Bulanık mantığın ardındaki ana fikir, keskin sınırları kullanmak yerine yumuşak sinırlar kullanmaktır (Zadeh, 1965). Klasik küme teorisinde, bir unsur ya bir dizinin üyesidir ya da üyesi değildir. Aksine bulanık kümede, 0 ile 1 arasında değişen, farklı derecelerde üyelik dereceleri bulunmaktadır. Bu özellik, bulanık çıkarım sistemini çok esnek bir araç haline dönüştürmektedir. Bir bulanık çıkarım sistemi girişler ve çıkışlar arasında bir bağlantı kurmaktadır.

Sukuk alanında yapılan bu çalışmada, bir girdi ve bir çıktı, iki girdi ve bir çıktı ile bulanık çıkarım sistemi kullanılmıştır. Sistem konfigürasyonu Şekil-1'de gösterilmiştir. Bulanık çıkarım sistemi üyelik fonksiyonları, mantıksal işlemler ve IF-THEN kuralları gibi bir takım bileşenleri kullanmaktadır. Üyelik fonksiyonları, bir bulanık kümedeki bir elemanın üyelik derecesini tanımlamak için kullanılmaktadır. Başka bir deyişle, bir öğenin bulanık kümeye kısmi olarak dahil edilmesi üyelik işlevleri tarafından tanımlanmaktadır. Bulanık mantık yaklaşımında bu işlevler büyük önem taşımaktadır ve bu nedenle dikkatli bir şekilde atanmaları gerekmektedir. Üçgen şekilli, çan şekilli ve trapez şekilli, literatürde en çok kullanılan üyelik fonksiyonlardır. Üyelik işlevleri, düşük, orta ve yüksek bulanık kümeler gibi dilsel bulanık sözcükleri kullanarak adlandırılmaktadır (Şekil-2). 


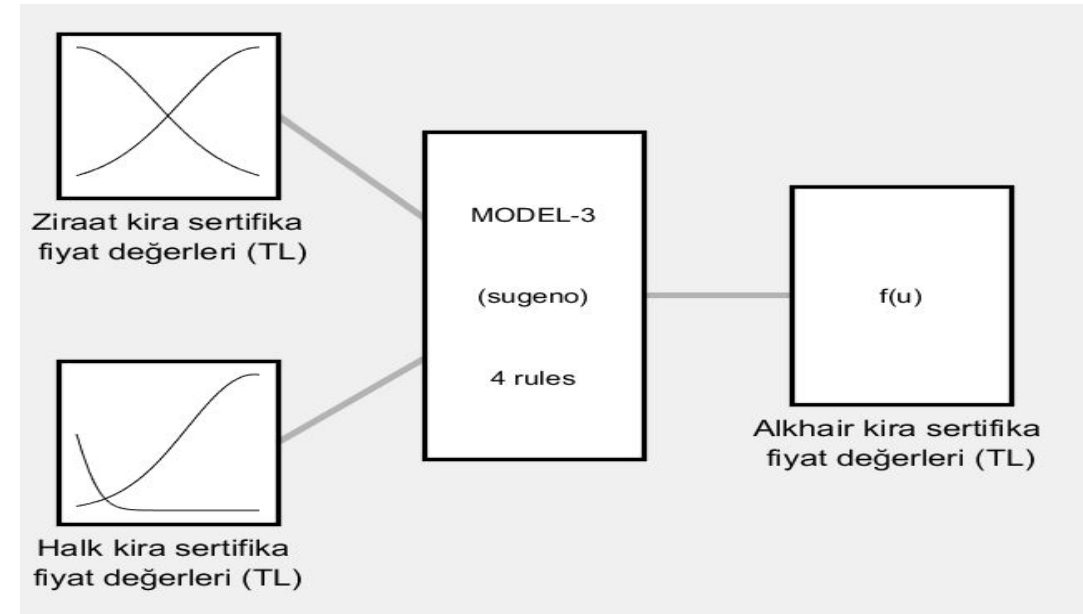

Şekil 1. Bulanık Çıkarım Sistemi Konfirigasyonu

Üyelik fonksiyonları bulanık IF-THEN kurallarının ağırlıklarını belirlemek için ve bu kurallar ise girdileri çıktılara bağlamak için kullanılmaktadır. Mamdani (1974) ve Takagi, Sugeno (1985) tarafindan önerilen iki farklı çıkarım sistemi mevcuttur. Mamdani yaklaşımı sözel verileri işleyebilir ve sayısal verilerin olmadığı durumlarda çok yararlı olabilmektedir. Öte yandan Takagi-Sugeno yaklaşımı, çok sayıda sayısal veri mevcut olduğunda etkili olmaktadır. Bu çalışmada Takagi-Sugeno yöntemini kullanılaarak modeller oluşturulmuştur. 

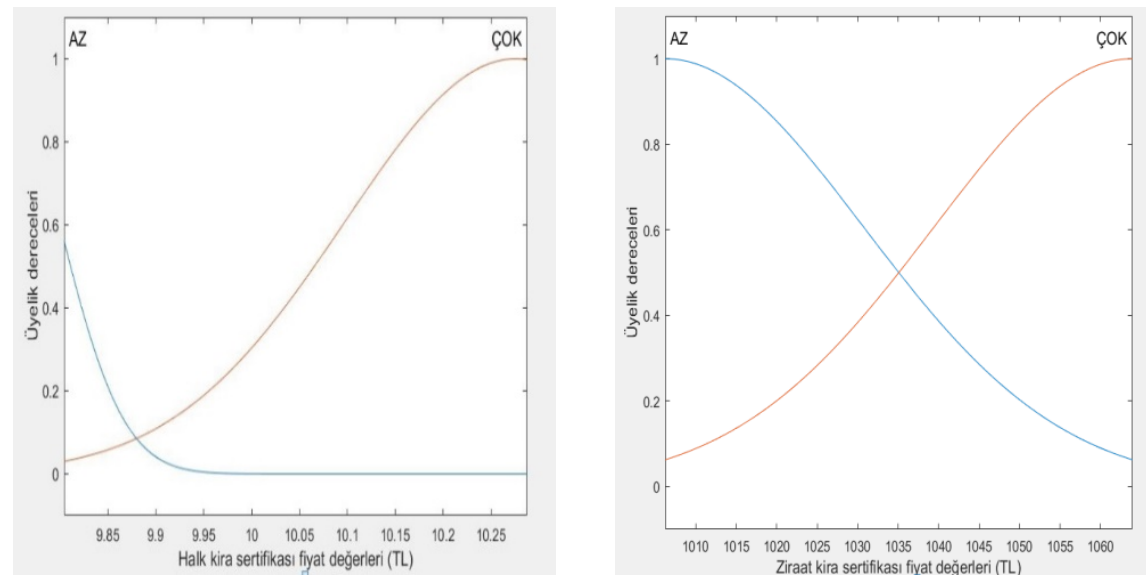

Şekil 2. Girdi Değerleri Üyelik Fonksiyonları

Bulanık mantık yöntemleri bulanık kuralları kullanarak girdi ve çıktılar arasındaki ilişkiyi tanımlamak için oluşturulmuştur. Yöntem, kullanıcıya varsayımlar yapmak yerine girdi verisinin belirsizliklerini dikkate almasını sağlamaktadır.. Başarılı bulanık mantık modellemesi için birbirine bağlı dört basamak takip edilmelidir:

Adım 1- Bulanıklaștırma: Girdi değerleri birbirine müdahale eden üyelik işlevlerine (bulanık kümeler) dönüştürülür. Bu çalışmada girdi olarak tanımlanan değerler için Gauss biçimli ve trapez biçimli fonksiyonlar modele dahil edilmiştir. Bulanık kümelerin adlandırılması için düşük, orta ve yüksek gibi dilsel bulanık terimler kullanılır.

Adım 2- Bulanık Kuralları Oluşturma: Bulanıklaştırma işleminden sonra, kombine dilsel girdi bulanık kümeleri ile çıktı bulanık kümeleri arasındaki ilişkiler bir dizi IFTHEN kuralları kullanılarak oluşturulur. İfadeler kuralların 'öncül' parçası olarak anılır ve dilsel girdi bulanık kümelerini birleştirir. 'IF' 'ifadelerinden sonra gelen ifadeler, öncül parçaya dayalı uygun çıtı bulanık kümelerini içeren kuralların 'sonuçta' parçası olarak adlandırılır. Bulanık kurallar, uzman bilgi ve / veya sentetik verilerin oluşturulmasını gerektirir. Bu çalışmada sukuk verileri tahmini için 2 kural geliştirilmiştir (Tablo-1).

Adım 3- Çıkarım: Nihai çıktı bir çıkarım sistemindeki tüm kurallara dayandığından, bunları belirli bir şekilde birleştirmek gerekir. Toplama, her kuralın çıktısını tek bir 
değere dönüştürmesine yardımcı olur. Çıkarım yöntemi ile şekillendirilmiş olan, her kuralın sonuç bölümünü basitçe toplanarak hesaplanır.

Adım 4- Durulaștırma: Son adım olarak, durulaştırma, birleştirilmiş çıktıları, ağırlıklı ortalamalarını kullanarak tek bir sayıya çevirir (Altunkaynak, 2010).

Jang (1993) tarafından önerilen uyarlamalı ağ tabanlı bulanık çıkarsama sistemi olan ANFIS yöntemi, hibrid bir öğrenme algoritması kullanarak üyelik fonksiyonlarının parametrelerini ve sonuç bölümünü optimize etmek için uygulanmaktadır. Bulanık model parametrelerini belirlemek için çeşitli yaklaşımlar önerilmiştir. Bu yaklaşımların birçoğu kümeleme teknikleri, genetik algoritmalar, gradyan iniş algoritmaları ve sayısal veriler kullanmaktadır. Ancak Jang (1993), sinir ağı geri-yayılım öğrenme algoritmasının basit ve etkili yöntemlerini üyelik fonksiyonlarının parametrelerini belirlemek için kullanmıştır. Girdiler ve üyelik fonksiyonları bulanık çıkarım sisteminin solunda, çıktılar ve denklemler sağda görünmektedir. Bu parametreleri hesaplamak için MATLAB'ın bulanık mantık araç kutusu kullanılmaktadır.

Tablo 1. Model-3 Bulanık Mantık Kural Tabanı

Kural Tanım

1) Ziraat az ve Halk az ise Alkhair $=$ Ziraat *-23+Halk*109.2+0.3067

2) Ziraat az ve Halk çok ise Alkhair $=$ Ziraat *126.9+Halk*32.02-1.09

3) Ziraat çok ve Halk az ise Alkhair = Ziraat *280.3+Halk*-26.11-2.475

4) Ziraat çok ve Halk çok ise Alkhair $=$ Ziraat $* 0.50+$ Halk*46.56 +0.1435

Takagi-Sugeno bulanık sistem için IF-THEN kontrol kuralları aşağıdaki şekilde verilmiştir:

$\mathrm{R}_{\mathrm{r}}: \operatorname{EGGER}\left(\mathrm{x}_{1} \mathrm{~A}_{\mathrm{r}}^{(1)}, \mathrm{x}_{2} \mathrm{~A}_{\mathrm{r}}^{(2)}, \ldots \ldots, \mathrm{x}_{\mathrm{n}} \mathrm{A}_{\mathrm{r}}^{(\mathrm{n})}\right) \operatorname{ISE} \mathrm{y}_{\mathrm{r}}=\mathrm{f}_{\mathrm{n}}\left(\mathrm{x}_{1}, \mathrm{x}_{2}, \ldots \ldots, \mathrm{x}_{\mathrm{n}}\right) \operatorname{dir}$.

Denklemde bulunan $\mathrm{R}_{\mathrm{r}}=$ r'nci kural, $\mathrm{A}_{\mathrm{r}}^{(1)}=$ dilsel üyelik fonksiyonunu, $\mathrm{f}_{\mathrm{n}}=$ fonksiyon, $\mathrm{y}_{\mathrm{n}}=$ çıktı değişkeni, $\mathrm{x}_{\mathrm{n}}=$ girdi değişkeni ve $\mathrm{n}=$ girdi sayısını göstermektedir. Genel olarak Takagi-Sugeno algoritması aşağıdaki şekilde oluşturulmaktadır:

1. Her bir $\mathrm{R}_{\mathrm{r}}$ ve $\mathrm{y}_{\mathrm{i}}$ için $\mathrm{f}_{\mathrm{i}}$ ler hesaplanır,

$\mathrm{y}_{\mathrm{r}}=\mathrm{f}_{\mathrm{r}}\left(\mathrm{x}_{1}, \mathrm{x}_{2}, \ldots . \mathrm{x}_{\mathrm{n}}\right)=b_{r}^{0}+b_{r}^{0} \mathrm{x}_{1}+\ldots . b_{r}^{n} \mathrm{x}_{\mathrm{n}}$

Denklem [1]

2. Ağırlıklar hesaplanır, 
Sule Yüksel Yï̆İTER

$\mathrm{r}_{\mathrm{r}}=\left(m_{1}^{r} \wedge m_{2}^{r} \wedge \ldots m_{s}^{r}\right) * \mathrm{R}_{\mathrm{r}}$

Denklem [2]

Burada $m_{1}, m_{2}, \ldots . m_{s} r$ 'nci kurala göre üyelik kesim değerini, $R_{r}=$ olasılığg,$\Lambda=$ en küçükleme operatarünü vermektedir. Basit olması adına $R_{r}$ bire eşitlenir.

3. Son olarak y çıktısı $\mathrm{r}_{\mathrm{r}}$ ve $\mathrm{y}_{\mathrm{r}}$ lerin ağırlıklı ortalaması olarak hesaplanır.

$\mathrm{y}=\frac{\sum_{T=1}^{\mathrm{n}} r_{r} * y_{y}}{\sum_{Y=1}^{\mathrm{n}} r_{Y}}$

Denklem [3]

\section{B. Model Performansının Tespiti}

Oluşturulan modellerin başarılı tahminler yaptığına dair göstergelerin kullanılması, tüm modelleme çalışmalarının en önemli parçalarından biridir. $\mathrm{Bu}$ çalışmada model başarılarının test edilmesinde hata kareleri ortalaması ve verimlilik katsayısı denklemlerinden yararlanılmaktadır. Hata kareleri ortalaması ve verimlilik katsayının detaylı açıklamaları aşağıda verilmiştir (Nash ve Sutcliffe, 1970).

$\mathrm{HKO}=\frac{1}{n} \sum_{i=1}^{n_{p}}\left(K_{g i}-K_{t i}\right)^{2}$

Denklem [4]

$\mathrm{VK}=1-\left[\frac{\sum_{\mathrm{i}=\mathrm{i}}^{\mathrm{n}}\left(K_{\mathrm{ti}}-K_{g i}\right)^{2}}{\sum_{\mathrm{i}=\mathrm{i}}^{\mathrm{n}}\left(K_{g i}-K_{g}\right)^{2}}\right]$

Denklem [5]

Denklemlerde bulunan $K_{g i}=\mathrm{KSF}$ değerlerinin gözlenen değerini, $K_{t i} \mathrm{KSF}$ değerlerinin tahmin değerini, $n=$ veri sayısını ifade etmektedir. Hata kareleri ortalaması değerinin 0 yaklaşması modelin hatasının azalmakta olduğunun göstergesidir.

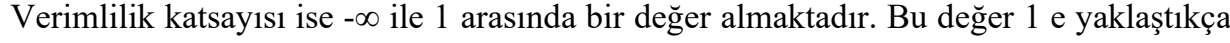
modelin çok başarılı tahminler yaptığını belirtmektedir. Bu değerin 0.5 den küçük olması zayıf bir tahminin olduğunu 0.8-1 arasındaki tahminlerin ise başarılı tahminler olduğunu belirtmektedir (Başakın, Özger ve Ünal, 2019: 758-759).

\section{Uygulama}

Bu çalışmada sukuk alanında Türkiye' de işlem gören 4 şirketin Ziraat, Halk, Alkhair, Azimut 24.08.2016-04.08.2017 tarihleri arasındaki 252 adet günlük kira sertifikası fiyat değerleri (KSF) verisi kullanılmıştır. Şirketler arasında korelasyon matrisleri oluşturularak (Tablo-2) arasında en iyi ilişkinin bulunduğu üç şirketin verisi model çalışmaları için seçilmiştir. Tablo 2 incelendiğinde Alkhair şirketi değerleri ile en yakın ilişkiye sahip şirketlerin 0.998 korelasyon değeri ile Halk ve Ziraat (KSF) olduğu görülmektedir. Ziraat ve Halk şirketinin kira sertifikası fiyat değerleri kullanılarak Alkhair şirketinin kira sertifikası fiyat değerleri tahmin edilmeye 
çalışılmıştır. Ayrıca Ziraat ve Halk şirketi değerleri ile Alkhair şirketinin 1, 3 ve 7 gün sonra olması muhtemel değerleri öngörülmüştür. Bu özelliği ile çalışma sukuk alanında ve bulanık mantık yöntemiyle modellenmesi ile bir ilk olma özelliği taşımaktadır.

Tablo 2. Sukuk Şirketleri Kira Sertifikası Fiyat Değerleri Değeri Korelasyon Matrisi

\begin{tabular}{|l|l|l|l|l|}
\hline & Halk(KSF) & Ziraat(KSF) & Azimut(KSF) & Alkhair(KSF) \\
\hline Halk(KSF) & 1 & 0.998 & 0.844 & 0.998 \\
\hline Ziraat(KSF) & & 1 & 0.853 & 0.998 \\
\hline Azimut(KSF) & & & 1 & 0.837 \\
\hline Alkhair(KSF) & & & & 1 \\
\hline
\end{tabular}

Bulanık mantık sistemi ile toplamda 9 model oluşturulmuştur. Bu modeller Ziraat KSF değerlerinin girdi Alkhair KSF değerlerinin ise çıktı olduğu, Halk KSF değerlerinin girdi Alkhair KSF değerlerinin çıktı olduğu ve Ziraat KSF ile Halk KSF değerlerinin beraber girdi olarak kullanıldığı yine Alkhair KSF değerinin çıktı olduğu modelleri kapsamaktadır. Model tabloları aşağıda (Tablo-3) verilmiştir.

Tablo 3. ANFIS Model Tablosu

\begin{tabular}{|c|c|c|c|}
\hline & Girdi & Yöntem & Çıktı \\
\hline Model 1 & $\mathrm{KSF}_{\text {Halk }(\mathrm{t})}$ & ANFIS & $\mathrm{KSF}_{\text {Alkhair(t) }}$ \\
\hline Model 2 & $\mathrm{KSF}_{\text {Ziraat(t) }}$ & ANFIS & $\mathrm{KSF}_{\text {Alkhair(t) }}$ \\
\hline Model3 & $\mathrm{KSF}_{\text {Halk }(\mathrm{t})}, \mathrm{K}_{\text {Ziraat }(\mathrm{t})}$ & ANFIS & $\mathrm{KSF}_{\text {Alkhair(t) }}$ \\
\hline Model 4 & $\mathrm{KSF}_{\text {Halk }(\mathrm{t}-1)}$ & ANFIS & $\mathrm{KSF}_{\text {Alkhair(t) }}$ \\
\hline Model 5 & $\mathrm{KSF}_{\text {Halk }(\mathrm{t}-3)}$ & ANFIS & $\mathrm{KSF}_{\text {Alkhair(t) }}$ \\
\hline Model 6 & $\mathrm{KSF}_{\text {Halk(t-7) }}$ & ANFIS & $\mathrm{KSF}_{\text {Alkhair(t) }}$ \\
\hline Model 7 & $\mathrm{KSF}_{\text {Ziraat(t-1) }}$ & ANFIS & $\mathrm{KSF}_{\text {Alkhair(t) }}$ \\
\hline Model 8 & $\mathrm{KSF}_{\text {iraat }(\mathrm{t}-3)}$ & ANFIS & $\mathrm{KSF}_{\text {Alkhair(t) }}$ \\
\hline
\end{tabular}


Sule Yüksel YİĞITER

Model 9

$\mathrm{KSF}_{\text {iraat }(\mathrm{t}-7)}$

ANFIS

$\mathrm{KSF}_{\text {Alkhair(t) }}$

Modelleme çalışmalarında girdi değerlerini bulanıklaştırmak için gauss şekilli fonksiyonlar ve trapez şekilli fonksiyonlar kullanılmıştır. Üyelik fonksiyonunun seçimi için literatürde bir netlik olmadığı için üyelik fonksiyon tipi deneme yanılma yolu ile seçilmiştir. KSF modelleri sırası ile ilk yüzde 60’lık kısmı ile eğitilmiş ve kalan yüzde 40’lık kısmı ile test edilmiştir. Küme sayısı olarak 3 alt küme sayısı en iyi sonuçları veren alt küme sayısı olarak tespit edilmiştir. Alt küme sayısı arttırılmış fakat test değerlerinin tahmininde başarı düşmüştür. Uygun küme sayısı 3 olarak belirlenmiştir. Uygulama kapsamında Alkhair KSF değerlerinin, 1, 3, 7 gün ileriye dönük tahminleri yapılmıştır.

\section{Bulgular}

Tahmin sonuçlarından en yüksek başarıya sahip modelin MODEL-3 olduğu görülmüştür. Verimlilik katsayısı ve hata kareleri ortalamaları değerlerine incelenirse, MODEL-3 0.985 VK ve 0.0111 HKO değeri ile yüksek başarıya sahip bir model olmuştur. MODEL-3'e ait dağılım grafikleri ve zaman serisi grafikleri Şekil-4'de verilmiştir. Ayrıca model sonuçları Tablo-4 de sunulmuştur.

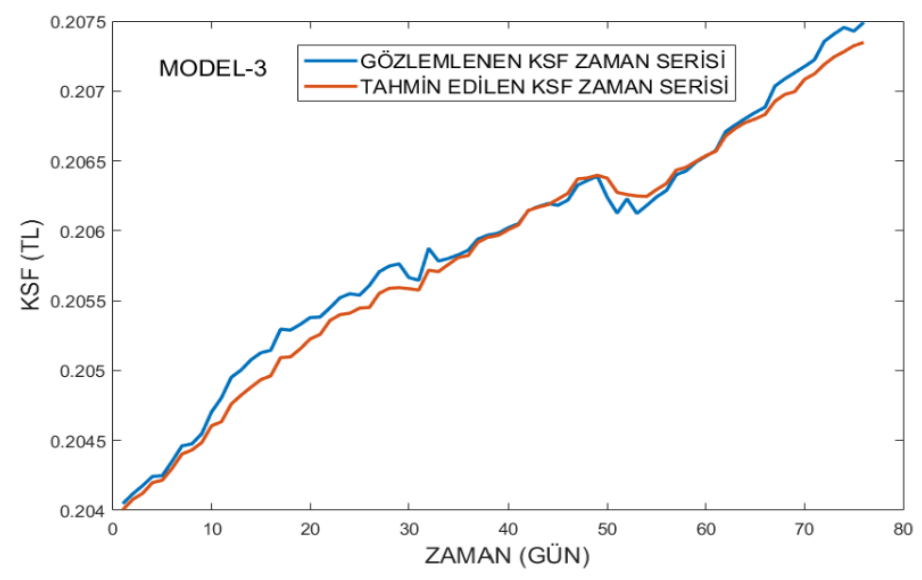

a) 


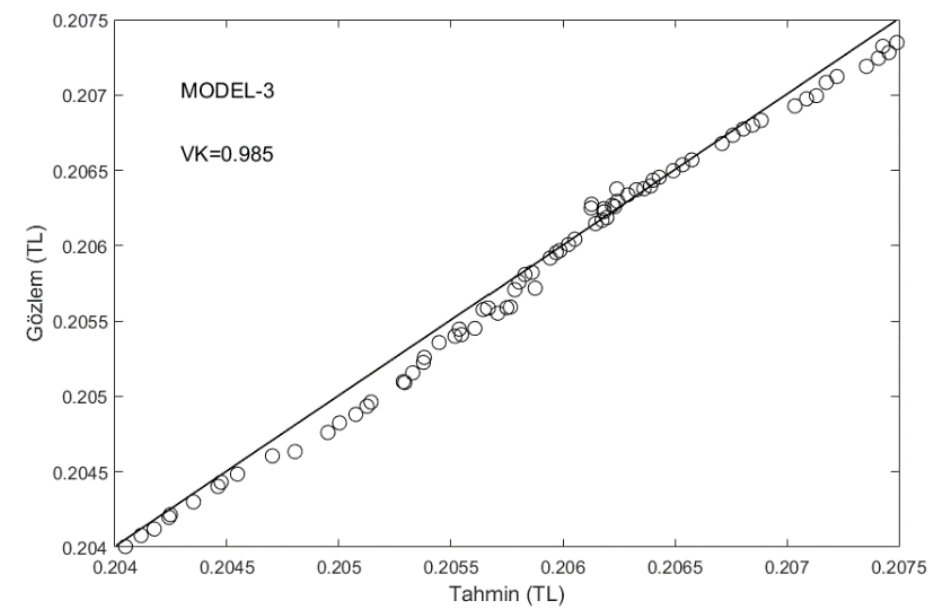

b)

Şekil 4. a)Tahmin edilen zaman serisi ve gözlemlenen zaman serisi grafik gösterimi, b)Tahmin-gözlem aşçılım grafiği

Model-3'de dağılım grafiği incelendiğinde tahmin edilen değerler ile gerçekleșen değerlerin mükemmel model çizgisi olarak adlandırılan çizginin üzerinde dağıldığ 1 görülmüştür. Mükemmel model çizgisi 1:1 doğrusu olarak da adlandırılmaktadır. $\mathrm{Bu}$ çizgi \%100 başarıyı temsil etmektedir. Çizgi üzerinde seyreden dağılım "üst tahmin" çizgi altında seyreden dağılım "alt tahmin" ve çizginin tam üstünde gerçekleşen dağılım ise "uygun tahmin" değerlerini temsil etmektedir. Şekil-4 incelendiğinde bazı noktalarda alt tahmin ağır bassa da genel itibari ile ortalama olarak uygun tahmin dağılımı olduğu çıkarımı yapılabilmektedir. İleriye dönük yapılan tahminlerde, 3 gün sonrası için VK değeri $0.95,7$ gün sonrası için yapılan tahmin modelinde VK değeri 0.945 olarak gerçekleşmiştir. Gözlenen bu VK değerleri, gayet başarılı bir tahmin gerçekleştiğinin göstergesi olarak yorumlanabilir. Bir hafta sonrası için yapılan tahminlerin başarılı sonuçlar verdiği gözlemlenmiş olup bu modeller sayesinde karar alma süreçlerinin daha da uzun süreli şekilde yapılabilmesinin önü açılmıştır. 
Șule Yüksel Yí̆̈ITER

Tablo 4. HKO ve VK Değerleri

\begin{tabular}{|l|l|c|c|}
\hline & \multicolumn{1}{|c|}{ Girdi } & $\begin{array}{c}\text { Hata Kareleri Ortalamas1 } \\
(\mathrm{HKO})\end{array}$ & $\begin{array}{c}\text { Verimlilik Katsay1s1 } \\
(\mathrm{VK})\end{array}$ \\
\hline Model1 & $\mathrm{KSF}_{\text {Halk(t) }}$ & 0.0207 & 0,972 \\
\hline Model2 & $\mathrm{KSF}_{\text {Zirat(t) }}$ & 0.0323 & 0.958 \\
\hline Model3 & $\begin{array}{l}\mathrm{KSF}_{\text {Halk(t), }} \\
\mathrm{K}_{\text {Zirat(t) }}\end{array}$ & 0.0111 & $\mathbf{0 . 9 8 5}$ \\
\hline Model4 & $\mathrm{KSF}_{\text {Halk(t-1) }}$ & 0.0282 & 0.962 \\
\hline Model5 & $\mathrm{KSF}_{\text {Halk(t-3) }}$ & 0.0485 & 0.935 \\
\hline Model6 & $\mathrm{KSF}_{\text {Halk(t-7) }}$ & 0.0898 & 0.827 \\
\hline Model7 & $\mathrm{KSF}_{\text {Ziraat(t-1) }}$ & 0.0329 & 0.956 \\
\hline Model8 & $\mathrm{KSFZ}_{\text {iraat(t-3) }}$ & 0.0353 & 0.95 \\
\hline Model9 & $\mathrm{KSFZ}_{\text {iraat(t-7) }}$ & 0.0281 & 0.946 \\
\hline
\end{tabular}

\section{Sonuç}

Bulanık mantık yöntemi kullanılarak sukuk kira sertifikası fiyat değerlerinin ileriye dönük tahmininin yapıldığı bu çalışmada, bulanık mantık yönteminin sukuk alanındaki kullanılabilirliği araştırılmış ve olumlu sonuçlar gözlenmiştir. Alkhair şirketinin KSF değerlerinin tahmini için aynı sektörde faaliyet gösteren 3 şirketten en iyi korelasyona sahip iki şirket seçilmiştir. Ziraat ve Halk şirketinin KSF değerleri kullanılarak Alkhair şirketinin KSF değerleri tahmin edilmeye çalışılmıştır. Verilerin belirli oranda eğitim ve test değerlerine ayrıştırılması sonucu oluşturulan modeller ile 1,3 ve 7 gün ilerisi için tahminlerde bulunulmuştur.

Çalışma sayesinde verisi bulunmayan şirketlerin verilerinin tahmini ya da ileride olması muhtemel ekonomik hareketlilikler, aynı kulvardaki diğer şirketlerin ekonomik hareketliliklerinden tahmin edilebilecektir. Bu çalışma sukuk alanında araştırma yapmak isteyen araştırmacılara 1şık tutması bakımından önem arz etmektedir. Farklı 
yöntemlerin bulanık mantık yöntemine adapte edilmesi ile oluşturulabilecek yeni çıkarım sistemleri ile ekonomik karar verme süreçleri hızlanabilir ve yatırımcıların daha düşük riskler ile alış veriş yapmalarının önü açılmış olacaktır. Bağımsız değişkenlerin devreye sokularak oluşturulacak modellerin ise başarıyı büyük oranda etkilemesi düşünülmektedir.

\section{Kaynaklar}

Accounting and auditing organization for islamic financial institutions (AAOIFI), Accounting, Auditing and Governance Standards, 2010.

Altunkaynak, A. (2010). A predictive model for well loss using fuzzy logic approach, Hydrological Processes, 24(17), 2400-2404. doi:10.1002/hyp.7642.

Arundina, T., Omar , M.A. ve Kartiwi, M. (2015). The predictive accuracy of sukuk ratings; multinominal logistic and neural network inferences, Pacific-Basin Finance Journal 34, ss.273-292.

Başakın, Eyyup. E.; Özger, Mehmet; Ünal, Necati. E. (2019). Gri Tahmin Yöntemi ile İstanbul Su Tüketiminin Modellenmesi. Politeknik Dergisi, 22(3), 755-761.

Cheng, H. C., Cheng, W. C. ve Wang W. W. (2008). Multi-attribute fuzzy time series method based on fuzzy clustering, Expert Systems with Applications 34, ss. 1235 1242.

Chu, H. H., Chen, T. L., Cheng, C. H. ve Huang,C. C. (2009). Fuzzy dual-factor timeseries for stock index forecasting, Expert Systems with Applications 36, ss. 165-171.

Hassan, M. R., Ramamohanarao, K., Kamruzzaman, J., Rahman, M.ve Hossain M. M. (2013). AHMM-bazed adaptive fuzzy inference system for stock market forecasting, Neurocomputing 104, ss.10-25.

Hazine Müsteşarlığı, Hazine Finansman Programı:2015 Yılı Gelişmeleri Ve 2016 Y1lı Öngörüleri, https://www.hazine.gov.tr/tr-TR/Duyuru-Listesi-Sayfasi.(05.10.2017)

Huarng, K. ve Yu, H. K. (2005). A type 2 fuzzy time series model for stock indeex forecasting, Physica A 353, 19 March, ss. 445-462.

IIFM, Sukuk Report 1 st Edition, 2010

Jang, J. S. R. (1993). Anfis - adaptive-network-based fuzzy inference system, Ieee Transactions on Systems Man and Cybernetics, 23(3), 665-685.

Kim, K. ve Han, I. (2000). Genetic algorithms approachto feature discretization in artifical neural networks for the prediction of stock price index, Expert Systems with Applications 19, ss. 125-132.

Kim, M. J., Han, I. ve Lee, C. (2004). Hybrid knowledge integration using the fuzzy genetic algorithm: prediction of the Korea Stock Price Index, 


$\mathbf{1 2 4 7} \begin{aligned} & \text { Şule Yüksel YíĞITER } \\ & \text { Salim Sercan SARI } \\ & \text { Eyyup Ensar BASSAKIN }\end{aligned}$

Intelligent Systems in Accounting, Finance and Management 12, Published online in Wiley Inter Science, ss. 43-60.

Kimoto, T., Asakawa, K., Yoda, M. ve Takeoka, M. (1990). Stock market prediction system with moduar neural networks, IJCNN International Joint Conference on San Diego, ss. 1-6

Liu, H.T., ve Wei, M.L. (2010). An improved fuzzy forecasting method for seasonal time series, Expert Systems with Applications 37, ss.6310- 6318.

Majhi, B. ve Anish C. M. (2015). Multiobjective optimization based adaptive models with fuzzy decision making for stock market forecasting, Neurocomputing 167, ss.502-511.

Mamdani, E. H. (1974). Application of fuzzy algorithms for control of simple dynamic plant. Electrical Engineers, Proceedings of the Institution of, 121(12), 1585-1588. doi:10.1049/piee.1974.0328.

Nagano, M. (2016). Who issues sukuk and when?: An analysis of the determinants of islamic bond issuance, Rewiew of Financial Economics 31, ss. 45-55.

Nan, G., Zhou, S., Kou, J. ve Li, M. (2012). Heuristic biavariate forecasting model of multi- attribute fuzzy time series based on fuzzy clustering, International Journal of Information Technology \& Decision Making, Vol. 11, No. 1, ss. 167- 195.

Nash, J. E., and Sutcliffe, J. V. (1970). "River Flow Forecasting through Conceptual Models. Part 1: A Discussion of Principles.” J. Hydrol., 10 (3), 282 290.

Shuaa Capital, Analysis of the Sukuk Market, 2007.

Smaouia, H. ve Nechi, S. (2017). Does sukuk market development spur economic growth?, Research in International Business and Finance 41, ss. 136-47.

Sun, B., Guo, H., Karimi, H. R., Ge, Y. ve Xiong, S (2015). Prediction of stock index futures prices based on fuzzy sets and multivariate fuzzy time series, Neurocomputing 151, ss.1528-1536.

Takagi, T., \& Sugeno, M. (1985). Fuzzy identification of systems and its applications to modeling and control. IEEE Transactions on Systems, Man, and Cybernetics, SMC-15(1), 116-132. 
Yiğiter Ş.Y., Sari S.S. ve Başakın E.E. (2017).Hisse senedi kapanış fiyatlarının yapay sinir ağları ve bulanık mantık çıkarım sistemleri ile tahmin edilmesi, Kahramanmaraş Sütçü İmam Üniversitesi İktisadi ve İdari Bilimler Fakültesi Dergisi, vol.7, pp.1-22

Yu, T. H. K. ve Huarng K. H. (2010). A neural network-based fuzzy time series model to improve forecasting, Expert Systems with Applications 37, ss. 3366-3372.

Wang, C. C. (2011). A comparison study between fuzzy time series model and ARIMA model for forecasting Taiwan Export, Expert Systems with Application 38, ss9296-9304.

Wei, L. Y. (2016). A Hybrid ANFIS model based on empirical mode decomposition for stock time series forecasting, Applied Soft Computing 42, ss. $368-376$.

Wong, H. L., Tu, Y. H. ve Wang C. C. (2010). Application of fuzzy time series models for forecasting the amount of Taiwan Export, Expert Systems with Applications 37, ss.1465-1470.

Zarandi, M. H. F., Hadavandi, E. ve Turksen, I. B. (2012). A hybrid fuzzy intelligent agent-based system for stock price prediction, International Journal of Intelligent Systems, Volume 27, Issue 11, November, ss. 947969.

Zadeh, L. A. (1965). Fuzzy sets. Information and Control, 8(3), 338-353. doi:http://dx.doi.org/10.1016/S0019-9958(65)90241-X 